\section{Injury prevention: blurring the distinctions between home and work}

\section{G S Smith}

\section{Home and work injuries share many of the same characteristics}

$\mathrm{T}$ his issue of Injury Prevention contains three articles about work related injury, the most for any regular issue of the journal. Their inclusion is part of the increasing recognition of occupational injury prevention as part of the mainstream injury prevention movement. It also puts the journal in the forefront as the leading multidisciplinary journal in the field of injury prevention, a direct result of the decision several years ago to expand its focus to cover all injuries, not just those to children and adolescents. Since then, in addition to the occupational injury supplement to the September 2001 issue, ${ }^{1}$ there have been seven other work related articles covering the spectrum from hand injury prevention among sugar cutters in India to fatal electrocutions in the US.

Injuries off the job are also receiving increasing attention by industry because of their impact on the workplace, both in terms of cost and lost productivity. For example, the National Safety Council estimates that for every worker killed on the job in the US, eight workers are killed off the job at home or on the highway. ${ }^{2}$ The workplace is also adversely impacted by injuries to family members. The costs of medical care and time off work to care for injured family members are largely paid for by employers, particularly when health insurance is provided through the workplace. It is estimated, for example that $63 \%$ of all unintentional injury deaths are to workers or their immediate family, most of which occur off the job. Unfortunately similar data are not available for non-fatal injuries.

\section{NATURAL EXPERIMENTS AND INJURY TRENDS}

There is wide variation in occupational injury rates by country and they are often greater than for other injuries. For example, using the United Kingdom as a benchmark, occupational fatality rates for the US and New Zealand are almost four times higher, Australia and Canada are five times higher, and Spain has a rate more than seven times that in the UK. ${ }^{3}$ The UNICEF report of child injury deaths which has been the topic of considerable discussion in this journal, ${ }^{4}$ however, reports only about a twofold increase in child injury fatalities over the UK rates for the same five mentioned countries (range 1.3-2.3). Differences in reporting practices that may bias these reported rates, ${ }^{5}$ cannot account for the huge discrepancies. Such wide variations in occupational mortality rates in relatively similar countries suggest that there is much each country can learn from the other. In fact these variations may represent opportunities to observe natural experiments based on differences in practices between countries, thus suggesting important new injury etiologies or intervention strategies. However, as noted by John Langley we need detailed examination of the multiple factors that may influence cross national differences (including examining specific causes) before such studies can provide meaningful guidance for the development of prevention strategies. ${ }^{6}$ The Towners' recent attempt to relate differences in child injury mortality rates to differences in injury prevention legislation is a step in this direction. ${ }^{4}$ Similar studies have not been done for workplace injuries and could lead to an improved understanding of the effect of factors such as work place safety regulation and changes in workplace practice on reducing injuries.

Examination of temporal trends in injury rates within the same country may also provide important insights into the evaluation of previously unrecognized natural experiments. The article by Loomis et al in this issue, examining trends in occupational injury mortality in the US is an example of one study that goes beyond simply describing overall injury trends. ${ }^{7}$ While they found a 3\% annual overall decline in all fatal occupational injuries in the US from 1980-96, the changes differ markedly by occupation and industry groups, gender, and by geographic region. Homicides at work showed little decline, although examination of individual differences by occupation and industry reveal more interesting findings that may suggest the effectiveness of certain prevention strategies. For example, homicide to employees at gasoline service stations declined over 5\% annually. One potential hypothesis is that most gasoline attendants now remain inside their cashier's booth and rarely venture out of their protected environment, especially at night. On the other hand, taxi drivers, who work in a much less protected environment showed a significant increase (over 3\% annually) in their homicide rate. Findings such as these suggest the need for more in-depth studies to examine the specific factors that may be responsible for these discrepancies and how we can apply the findings to implement effective prevention strategies. The expanded information available in the Census of Occupational Fatalities may provide insight into these issues. ${ }^{8}$ In addition, most studies of mortality trends ignore the influence of improved trauma care which can reduce injury mortality, without having any influence on the actual occurrence of injury. ${ }^{9}$

\section{EXPOSURE ASSESSMENT}

One of the most important issues to consider when examining any changes in injury rates is variation in exposure, an essential component of evaluating injury risk. ${ }^{10}$ As acknowledged by Loomis et al, the use of population data, such as number of people employed, fails to recognize how risk changes by varying levels of exposure. For example, motor vehicle fatality rates per million population changed little over time, while the rates per million miles traveled decreased dramatically as a result of factors such as improved roads and vehicle crashworthiness. ${ }^{11}$ In the occupational setting, exposure is more difficult to measure and hours worked is often used as a first level approximation. A comparison of population based occupational fatality rates with rates based on hours worked found that overall rankings of occupation or industry changed little in the US. ${ }^{12}$ However, because teenagers and the elderly tend to work less than those in middle age, their risk per work hour is considerably underestimated using a population based approach.

Occupation and industry is sometimes used as a surrogate for exposure in epidemiologic studies of the workplace. However, there have been large changes in the nature of work in specific occupations and industries over time, and as Loomis et al discuss, they are unable to account for issues such as these in their analysis. In addition some hazardous tasks have been exported overseas. More specific measures such as hours worked on a specific task or machine would provide more accurate assessments of risk, but are beyond the scope of articles such as the one under discussion. One of our challenges is to develop better methods of assessing exposure for occupational injuries in order to better estimate task specific risks. 
Driscoll et al in this issue make creative use of a survey of time spent on household tasks to develop exposure measures for their analysis of fatal injuries resulting from unpaid work at home, and contrast this with population based rates. ${ }^{13}$ Their measures provide a much more appropriate estimate of task specific injury risk, at least for the broad categories of activities available from the survey data. The ranking of the most hazardous household tasks did not change for men, but for women housework had the highest population based risk but the lowest risk based on hours of exposure.

\section{IMPROVING THE VALUE OF SURVEILLANCE}

One important advance in the use of surveillance data to do more than count cases, is the ability to recruit cases for more in-depth study of injury causes. However, routine injury surveillance systems often lack information on work relatedness. ${ }^{1}$ The study of nail gun injuries in residential carpenters in this issue illustrates well the value of an active surveillance program and its use to identify the factors associated with nail gun injuries. ${ }^{14}$ Despite case reports as far back as 1975 that identify problems with nail guns, they continue to cause severe injuries. The use of the National Electronic Injury Surveillance System (NEISS) to follow back on specific work related injuries, ${ }^{15}$ or for case control studies such as the effectiveness of protective gear at reducing injuries from in line skates ${ }^{16}$ are other examples of extending our use of surveillance data The case crossover method is also well suited to in-depth follow up of injury etiology from surveillance data, as it only involves interviews of cases and estimates individual exposed person-time at risk. $^{17}$

Insurance claims data also represent a potentially valuable source of cases for follow-back studies. For example, evaluating the effectiveness of child seat restraints requires data on all crashes involving children, not just those where a child is injured. Health system based studies of child seat restraints fail to capture the uninjured restrained population. A recent study enrolled a representative sample of all children involved in crashes at the time property damage claims are called into the insurance company, thus, enabling follow-back data to be collected on all crashes and their outcome. ${ }^{18}$ The use of insurance claims records for occupational injury research has been largely limited to disability and cost studies of workers' compensation claims, aside from studies such as those analyzing free text from claims. ${ }^{19}$ Studies such as the evaluation of child seat restraints using a large insurers claims unit for subject recruitment provide a useful model for future studies.

\section{INTEGRATION WITH \\ LABORATORY STUDIES}

One important issue not addressed by Lipscomb's article on nail guns is the need for follow up experimental studies to examine factors related to injuries and to design appropriate safety countermeasures. Their study clearly identified a problem with nail guns and the need to develop design changes. Many advances in injury prevention will come about through the integration of laboratory/ experimental studies with other public health disciplines. However, often laboratory orientated articles tend to be rather technical in nature and less comprehensive in relating their findings to prior epidemiologic studies on their topic, while public health studies frequently make little reference to experimental laboratory studies or use experimental data to guide their research. One example of the value of relating experimental and epidemiological studies is the study of the role of alcohol in the workplace. While acute alcohol use rarely seems to be involved in occupational injuries ${ }^{20}$ the recent experiments using maritime shipping simulators suggest that even very low blood alcohol levels can decrease occupational performance. ${ }^{21}$

While the need for a collaborative multidisciplinary effort to reduce workplace injuries is well recognized, it is often difficult to implement such ideas in practice. For example, funding agencies and study sections often have difficulty evaluating multidisciplinary research proposals. Another limitation is the difficulty of appropriate information retrieval from other disciplines. While occupational injury prevention is considered interdisciplinary, all too often published researchers reference only other research from their own discipline. As noted in a recent systematic review of occupational injuries, ${ }^{22}$ many of the publications cited would not have been picked up by a search of Medline but came from non-medical disciplines and government reports that require the use of other search engines such as NIOSHTIC, Transportation (includes TRIS), Psych INFO, and Ergonomic Abstracts. The problem may get even worse with the increasing availability of online, full text journals and the tendency to only refer to these as they are simpler (and less expensive) to access. In addition, many of the articles used in the reviews were located not by search engines, but by "pearled references" (those found hidden within other research reports), conference proceedings, and personal contacts. Increasing the links between public health disciplines and the experimental safety sciences can only serve to strengthen the relevance of each discipline to the broader issue of improving occupational safety.

\section{CHANGING NATURE OF WORK}

An important issue in any field is definitions, and the issue of what constitutes an occupational injury has always been difficult. The article by Driscoll et al in this issue on fatalities from unpaid work in and around the home is a good illustration of the complexity in considering these issues. ${ }^{13}$ Their study provides some of the first information on unpaid work, an area of increasing interest, which has unique occupational health and safety and concerns both in developed and less developed countries. ${ }^{23}$ In the course of reviewing coroners' records for work relatedness, the authors included unpaid home duties that could be performed for pay if done by someone else. The lead author also has a recent article in another journal that compares the classification of work relatedness for fatal injuries between Australia, New Zealand, and the US. ${ }^{24}$ One key issue in defining occupational injuries is how volunteer work is counted, as illustrated in a recent study of on the job fatalities in paramedics that include volunteers who perform occupational duties for no pay. ${ }^{25}$

As noted in my earlier commentary, the separation between work and nonwork injuries is becoming increasingly blurred, as these injuries often involve very similar mechanisms. For example, almost all the tasks involved in the unpaid work injuries fatalities described by Driscoll et al, ${ }^{13}$ such as car maintenance, ladder use and working on roofs, could also have been done for pay. In fact their increasing fatality rate in the elderly from performing these tasks suggests that maybe some of these tasks should have been hired out rather than done by the elderly homeowner. The aging of the population (including those in the workforce) presents some unique prevention challenges both at home and at work. ${ }^{26}$

\section{CONCLUSION}

Some members of the injury prevention community may still consider occupational injuries to be a separate entity from other injuries and may skip over articles that seem not to be relevant to their interests. It is our hope that through the increasing profile of occupational injuries in this journal that readers will be able to learn from the cross fertilization of ideas across groups. Many of the same prevention strategies directed at occupational injuries are applicable outside the workplace, such as zero tolerance for drugs and alcohol, and use 
of protective devices. In fact, the controlled environment of the workplace may represent an opportunity to evaluate some community prevention strategies such as increasing seatbelt use.

In today's global business environment, with its increasing number of self employed, contractual and home based workers, many workplaces are not covered by regulatory agencies such as the Occupational Safety Health Administration. The rapid growth of telecommuting, for example, presents some unique health and safety challenges. ${ }^{27}$ Given the changing nature of the workplace, a new, comprehensive community approach to injury prevention is needed, one which takes into account the blurring of the lines between work and non-work environments that is increasingly prevalent in society. ${ }^{28}{ }^{29}$ It is important that we explore all the options at home and at work to reduce the global burden of injuries.

\section{Injury Prevention 2003;9:3-5}

\section{Author's affiliation}

G S Smith, Liberty Mutual Research Institute for Safety, Hopkinton, Massachusetts

Correspondence to: Dr Gordon Smith, Liberty Mutual Research Institute for Safety,

71 Frankland Road, Hopkinton, Massachusetts 01748, USA; Gordon.Smith@LibertyMutual.com

\section{REFERENCES}

1 Smith GS. Public health approaches to occupational injury prevention: do they work? Inj Prev 2001;7(suppl 1):i3-10.

2 Sinelnikov S, Lin M-L. The cost of off-the-job injury. Injury insights. National Safety Council. 2002 April/May: 1-2.
3 Takala J. Global estimates of fatal occupational accidents. Epidemiology 1999:10:640-6.

4 Towner E, Towner J. UNICEF's child injury league table. An analysis of legislation: mor mixed messages. Inj Prev 2002;8:97-100.

5 Feyer A-M, Williamson AM, Stout N, et al. Comparison of work related fatal injuries in the United States, Australia, and New Zealand: method and overall findings. Inj Prev 2001;7:22-8.

6 Langley J. International comparisons: we need to know a lot more. Inj Prev 2001;7:267-9.

7 Loomis D, Bena J, Bailer AJ. Diversity of trends in occupational injury mortality in the United States, 1980-1996. Inj Prev 2003;9:9-14

8 Biddle EA, Marsh SM. Comparison of two fatal occupational injury surveillance systems in the United States. I Safety Res 2002:33:337-54.

9 Yates D. Improving post-impact care-a form of injury prevention. Inj Prev 1998;4:S42-5.

10 Smith GS, Howland JH. Declines in drowning: exploring the epidemiology of favorable trends. JAMA 1999;281:2245-7.

11 Centers for Disease Control. Achievements in public health, 1900-1999 motor-vehicle safety: a 20th century public health achievement. MMWR Morb Mortal Wkly Rep 1999;48(18):369-74.

12 Ruser JW. Denominator choice in the calculation of workplace fatality rates. Am J Ind Med 1998;33:151-6.

13 Driscoll TR, Mitchell RJ, Hendrie AL, et al. Unintentional fatal injuries arising from unpaid work at home. Inj Prev 2003;9:15-19.

14 Lipscomb HJ, Dement JM, Nolan J, et al. Nail gun injuries in residential carpentry: lessons from active injury surveillance. Inj Prev 2003;9:20-4

15 Jackson LL. Non-fatal occupational injuries and illnesses treated in hospital emergency departments in the United States. Inj Prev 2001;7(suppl 1):i21-6.

16 Schieber RA, Branche-Dorsey CM, Ryan $\mathrm{GW}$, et al. Risk factors for injuries from inline skating and the effectiveness of safety gear. N Engl J Med 1996;335:1630-5.

17 Sorock GS, Lombardi DA, Gabel CL, et al. Case-crossover studies of occupational trauma: methodological caveats. Inj Prev $2001 ; 7$ (suppl 1):i38-42.

18 Durbin DR, Bhatia E, Holmes JH, et al. Partners for child passenger safety: a unique child-specific crash surveillance system. Accid Anal Prev 2001;33:407-12.

19 Sorock GS, Smith GS, Reeve GR, et al. Three perspectives on work-related injury surveillance systems. Am J Ind Med 1997;32:1 16-28.

20 Veazie MA, Smith GS. Heavy drinking alcohol dependence, and injuries at work among young workers in the United States labor force. Alcohol Clin Exp Res 2000;24:1811-9.

21 Howland J, Rohsenow DJ, Cote J, et al. Effects of low-dose alcohol exposure on simulated merchant ship piloting by maritime cadets. Accid Anal Prev 2001 ; 33:257-65.

22 Beahler CC, Sundheim JJ, Trapp NI. Information retrieval in systematic reviews: challenges in the public health arena. Am J Prev Med 2000;18(4 suppl):6-10.

23 Ironmonger $\mathbf{D}$. The value of care and nurture provided by unpaid household work. Family Matters 1994;37(April):46-51. Available at: http://www.aifs.org.au/institute/pubs/fm l / fm37di.html, accessed 1/15/03.

24 Driscoll T, Feyer A-M, Stout N, et al. Assessing the classification of work-relatedness of fatal incidents: a comparison between Australia, New Zealand and the United States. Ini Control Saf Promot 2002;9:32-9.

25 Maguire BJ, Hunting KL, Smith GS, et al. Occupational fatalities in emergency medical services: a hidden crisis. Ann Emerg Med 2002;40:625-32.

26 Benjamin KL, Pransky G. Occupational injuries and the older worker: challenges in research, policy and practice. Southwest J Aging 2001; 16:47-61

27 Healy ML. Telecommuting: occupational health considerations for employee health and safety. AAOHN J 2000;48:407.

28 Committee on Techniques for the Enhancement of Human Performance. Occupational analysis; the changing nature of work: implications for occupational analysis. Washington, DC: National Research Council. National Academy of Sciences Press, 1999.

29 Smith GS, Veazie MA. Principles of prevention: the public health approach to preventing injuries in the workplace. ILO encyclopedia of occupational health and safety. Geneva, Switzerland: International Labor Office, 1998:56:26-30. 